\title{
Kidney stone composition in overweight and obese patients: a preliminary report
}

\author{
This article was published in the following Dove Press journal: \\ Research and Reports in Urology \\ 9 January 2013 \\ Number of times this article has been viewed
}

\author{
Hisham A Mosli' \\ Hala $\mathrm{H}$ Mosli $^{2}$ \\ Wissam K Kamal' \\ 'Department of Urology, ${ }^{2}$ Department \\ of Internal Medicine (Endocrinology), \\ King Abdulaziz University Hospital, \\ Jeddah, Saudi Arabia
}

Objective: To report preliminary information on urinary stone composition in patients who are either overweight or obese with kidney stone disease.

Methods: A cohort of patients $(n=138)$ with nephrolithiasis were prospectively followed from January 2011 for 18 months. Of those, 64 (46\%) were found to be overweight with body mass index $\geq 25 \mathrm{~kg} / \mathrm{m}^{2}$ and $74(54 \%)$ were obese with body mass index $\geq 30 \mathrm{~kg} / \mathrm{m}^{2}$. Stone characteristics including size, location, and composition were studied in detail, and patients' age, weight, height, and gender were all documented. The stone size and location were studied radiologically while semiquantitative stone analysis was carried out using the DiaSys method, which involves titrimetric determination of calcium, colorimetric determination/visual assessment of oxalate, phosphate, magnesium, ammonium, uric acid, and cystine, and qualitative determination of carbonate.

Results: Eighteen stones were collected from overweight and obese patients. Those obtained were either spontaneously passed $(n=2)$, fragments passed following shockwave lithotripsy $(n=11)$, extracted ureteroscopically $(n=2)$, or extracted by percutaneous nephrolithotomy $(n=3)$. About $95 \%$ of the stones contained calcium oxalate and more than half contained uric acid.

Conclusion: This report confirms that kidney stones are mainly composed of calcium oxalate and uric acid in overweight and obese patients with nephrolithiasis.

Keywords: urolithiasis, nephrolithiasis, obesity, renal stone, body mass index (BMI), calculus, stone composition, analysis

\section{Introduction}

Obesity is implicated in the alarming worldwide escalation of the prevalence of renal stone disease. ${ }^{1,2}$ Stone formation is universally believed to be of multifactorial etiology including genetic, environmental, and hormonal interaction. ${ }^{3}$ It is established that as an overall end result of these factors, excessive excretion of stone forming components is produced which in turn results in urinary supersaturation of minerals and other elements in an environment that enhances precipitation and further crystal accumulation to form renal calculi. ${ }^{3}$ Most renal stones in real life are mixed stones; stones formed of a single element, such as pure uric acid stones, are rare. ${ }^{3}$

Obesity-associated indulgence in food and beverages rich in stone-forming dietary elements is a major factor responsible for the excessive secretion of elements such as oxalate, uric acid, and sodium. ${ }^{4}$ Increased body mass index (BMI) is one international representative of obesity shown not only to contribute to the increased prevalence of kidney stones but is also associated with larger stone sizes. ${ }^{5}$ This preliminary report 
further explores the end result product of the metabolic derangement that accompanies obesity such as increased excretion of calcium oxalate and uric acid and impaired secretion of hydrogen ion and crystallization inhibitory elements such as organic citrate. Currently, limited literature exists to confirm that this derangement produces stones that are mostly composed of oxalate and uric acid in stone patients of increased BMI. Here, a cohort of overweight and obese patients with renal stones was prospectively examined and the stone composition was studied in random sampling once the stone material became available either by spontaneous passage or when surgically removed. Gambaro et al published a recent paper which demonstrated that the physiochemical risk of calcium stone formation does not increase with metabolic syndrome (including obesity) when adjusted for most known dietary variables. Although they stated that it is unclear which type of stones are passed from patients with metabolic syndrome, they pointed out that these patients are at high risk for uric acid stones and that calcium oxalate stones might be very common. ${ }^{6}$

This preliminary report serves only to explore the actual stone composition of overweight and obese patients to confirm the end result of the metabolic disturbances that are said to occur in those patients. The clinical implications of this report are important since they involve better understanding of the pathogenesis of stone formation in overweight and obese patients, therefore improving the preventive measures of primary stone formation and avoiding or decreasing the notoriously known high recurrence rate. ${ }^{2}$ In addition, this information can be used to aid the planning of medical and surgical therapeutic measures. ${ }^{3}$ An advantage of this study over a related previous one is that the previous study was based on a "self-reporting" of stone events in only a small number of a large cohort, which did not outnumber the population studied in the current study. ${ }^{4}$ It is universally agreed that knowledge of stone composition based upon one of the accepted methods of stone analysis is a fundamental step in urinary stone management. ${ }^{7}$

\section{Methods}

A cohort of patients $(n=138)$ with nephrolithiasis was prospectively followed from January 2011 for 18 months. Of those, 64 (46\%) were found to be overweight with $\mathrm{BMI} \geq 25 \mathrm{~kg} / \mathrm{m}^{2}$ and $74(54 \%)$ were obese with $\mathrm{BMI} \geq 30 \mathrm{~kg} / \mathrm{m}^{2}$. Stone characteristics including size, location, and composition were studied in detail in addition to patients' age, weight, height, and gender. The stone size and location were studied radiologically mainly using noncontrast computed tomography scans, while semiquantitative stone analysis was carried out using the DiaSys method, which involves titrimetric determination of calcium, colorimetric determination/visual assessment of oxalate, phosphate, magnesium, ammonium, uric acid, and cystine, and qualitative determination of carbonate. The kits were purchased from DiaSys Diagnostic Systems GmbH (Holzheim, Germany). This wet chemical analysis test has good correlation to infrared spectrometry and X-ray examination and is a good economic alternative as no expensive equipment is needed in a standard hospital biochemistry laboratory. ${ }^{7}$

All participants signed an informed consent and the study was approved by the institution's clinical research committee.

\section{Results}

The male to female ratio in the study population was $3: 1$. The age range for males was $18-75$ years (mean $45.89 \pm 12.981$ ) and the age range for females was 25-79 years (mean $46.48 \pm 11.952)$. For the entire cohort, the age range was $18-79$ years (mean $46.03 \pm 12.707)$. Of the patients in this cohort, $30(21.7 \%)$ had a diagnosis of diabetes and $41(29.7 \%)$ had a diagnosis of essential hypertension.

Eighteen stones were collected from overweight and obese patients. Those obtained were either spontaneously passed $(n=2)$, fragments passed following shockwave lithotripsy $(n=11)$, extracted ureteroscopically $(n=2)$, or extracted by percutaneous nephrolithotomy $(n=3)$. Of the 18 stones, 17 (94.4\%) contained calcium oxalate of various percentages and ten $(55.5 \%)$ contained uric acid. Therefore, the majority of the stones contained calcium oxalate and more than half contained uric acid. The details of these results are summarized in Table 1 . These percentages were much higher compared to the global distribution of $80 \%$ calcium oxalate and $10 \%-15 \%$ uric acid in the general stone-forming patient population. ${ }^{3,4}$

\section{Discussion}

Identification of stone composition is a fundamental step in the metabolic evaluation of kidney stones. Nephrolithiasis is considered a recurrent, painful disease of major deleterious sequels. Obesity is partially blamed for the global rise in the prevalence rates of urinary stone disease among males and females. ${ }^{7}$

Links between nephrolithiasis and obesity, type 2 diabetes mellitus, and the metabolic syndrome as a whole have been shown previously. ${ }^{8}$ In type 2 diabetes mellitus, insulin resistance has been shown to lower the $\mathrm{pH}$ value of 
Table I Summary of the stone characteristics in obese and overweight patients

\begin{tabular}{|c|c|c|c|c|c|c|}
\hline No & Age (years) & Gender & BMI $\left(\mathrm{kg} / \mathrm{m}^{2}\right)$ & $\begin{array}{l}\text { Stone size, maximum } \\
\text { diameter }\end{array}$ & Stone composition & Stone location \\
\hline \multicolumn{7}{|c|}{ Obese: $\mathrm{BMI} \geq 30 \mathrm{~kg} / \mathrm{m}^{2}$} \\
\hline I & 57 & $\mathrm{~F}$ & 32.4 & Medium $\mathrm{I} . \mathrm{I} \times \mathrm{I} \mathrm{cm}$ & $\begin{array}{l}80 \% \text { calcium oxalate } \\
10 \% \text { ammonium } \\
10 \% \text { uric acid }\end{array}$ & Left lower calyx \\
\hline 2 & 41 & $\mathrm{~F}$ & 33.3 & Medium I $\times 2 \mathrm{~cm}$ & $\begin{array}{l}70 \% \text { cystine } \\
30 \% \text { calcium oxalate }\end{array}$ & Left renal pelvis \\
\hline 3 & 33 & M & 32.1 & Medium $1.5 \times 2 \mathrm{~cm}$ & $\begin{array}{l}70 \% \text { calcium oxalate } \\
30 \% \text { uric acid }\end{array}$ & Right middle calyx \\
\hline 4 & 62 & $\mathrm{~F}$ & 34.7 & Small $0.4 \times 0.3 \mathrm{~cm}$ & $\begin{array}{l}70 \% \text { uric acid } \\
20 \% \text { calcium oxalate } \\
10 \% \text { ammonium }\end{array}$ & Right lower calyx \\
\hline 5 & 37 & $\mathrm{~F}$ & 34.5 & Small $0.8 \times 0.3 \mathrm{~cm}$ & $\begin{array}{l}80 \% \text { carbonate apatite } \\
10 \% \text { calcium oxalate } \\
10 \% \text { ammonium } \\
\text { magnesium phosphate }\end{array}$ & Left upper calyx \\
\hline 6 & 58 & M & 32.3 & Large $4.6 \times 3.3 \mathrm{~cm}$ & $\begin{array}{l}60 \% \text { carbonate apatite } \\
30 \% \text { calcium carbonate } \\
10 \% \text { calcium oxalate }\end{array}$ & Right renal pelvis \\
\hline 7 & 44 & M & 33 & Small $0.7 \times 0.8 \mathrm{~cm}$ & $\begin{array}{l}50 \% \text { uric acid } \\
50 \% \text { calcium oxalate }\end{array}$ & Right lower calyx \\
\hline Ove & ght: $B M I \geq 25$ & & & & & \\
\hline 8 & 39 & M & 25.3 & Medium $1.7 \times 0.8 \mathrm{~cm}$ & $100 \%$ calcium oxalate & Left lower calyx \\
\hline 9 & 60 & M & 26.4 & Medium I.I $\times 0.8 \mathrm{~cm}$ & $\begin{array}{l}80 \% \text { calcium oxalate } \\
10 \% \text { uric acid } \\
10 \% \text { ammonium }\end{array}$ & Left middle calyx \\
\hline 10 & 33 & M & 29.6 & Large $3.1 \times 1.3$ & $\begin{array}{l}50 \% \text { uric acid } \\
30 \% \text { ammonium } \\
20 \% \text { calcium oxalate }\end{array}$ & Right lower calyx \\
\hline II & 61 & $M$ & 29.2 & Medium $1.9 \times 1.4 \mathrm{~cm}$ & $\begin{array}{l}80 \% \text { calcium apatite } \\
20 \% \text { calcium oxalate }\end{array}$ & Left renal pelvis \\
\hline 12 & $4 I$ & M & 29.9 & Large $2.8 \times 1.7 \mathrm{~cm}$ & $\begin{array}{l}80 \% \text { uric acid } \\
20 \% \text { ammonium }\end{array}$ & Left middle calyx \\
\hline 13 & 48 & M & 28.4 & Medium $1.3 \times 0.9 \mathrm{~cm}$ & $\begin{array}{l}90 \% \text { calcium oxalate } \\
10 \% \text { phosphate }\end{array}$ & Right lower calyx \\
\hline 14 & 59 & $M$ & 25.6 & Medium I.I $\times 0.4 \mathrm{~cm}$ & $\begin{array}{l}90 \% \text { calcium oxalate } \\
10 \% \text { phosphate }\end{array}$ & Left renal pelvis \\
\hline 15 & 43 & $M$ & 25.2 & Small $0.6 \times 0.35 \mathrm{~cm}$ & $\begin{array}{l}50 \% \text { carbonate } \\
40 \% \text { apatite } \\
10 \% \text { calcium oxalate }\end{array}$ & Right renal pelvis \\
\hline 16 & 39 & $M$ & 28.3 & Small $0.8 \times 0.6 \mathrm{~cm}$ & $\begin{array}{l}70 \% \text { calcium oxalate } \\
30 \% \text { uric acid }\end{array}$ & Left renal pelvis \\
\hline 17 & 41 & $\mathrm{~F}$ & 26.9 & Medium $1.3 \times 1.0 \mathrm{~cm}$ & $\begin{array}{l}90 \% \text { calcium oxalate } \\
10 \% \text { uric acid }\end{array}$ & Left renal pelvis \\
\hline 18 & 39 & M & 25.3 & Medium $1.7 \times 0.8 \mathrm{~cm}$ & $\begin{array}{l}90 \% \text { calcium oxalate } \\
10 \% \text { uric acid }\end{array}$ & Left lower calyx \\
\hline
\end{tabular}

Abbreviations: BMI, body mass index; F, female; $M$, male; No, number.

urine, thereby promoting the formation of uric acid stones. Obesity itself also promotes urine with a low $\mathrm{pH}$ as well as the increased excretion of calcium, oxalate, and uric acid, thereby also promoting the formation of uric acid stones. ${ }^{7,9}$

Obesity has been linked with some types of stones more than others, eg, uric acid and calcium oxalate stones compared with calcium phosphate or mixed calcium oxalate and calcium phosphate stones. ${ }^{9}$ The mechanism by which obesity contributes to urinary stone formation has not been clearly defined. Some studies have determined that obesity is associated with alterations in the chemical components of serum and urine such as phosphate, citrate, oxalate, and uric acid. ${ }^{7,910}$ However, the major contribution of obesity to renal calculi is through its relationship with overly acidic urine. ${ }^{10}$ 
Persistently acidic urine is known to be depleted from organic citrate, a potent crystallization inhibitory factor. ${ }^{9}$ Maalouf et al concluded that in patients with urolithiasis, urinary $\mathrm{pH}$ is inversely related to body weight, with a stepwise reduction in urinary $\mathrm{pH}$ observed with increasing body weight. ${ }^{11}$ The proposed mechanism for the reduced urinary $\mathrm{pH}$ in obese patients is thought to be through insulin resistance caused by visceral obesity, where low insulin bioactivity in the renal proximal tubule can theoretically lead to defective ammonium production and/or excretion, thus affecting urinary $\mathrm{pH} .{ }^{11}$ Maalouf et al described urinary $\mathrm{pH}$ as a marker for renal insulin sensitivity; as generalized insulin sensitivity decreases, renal insulin sensitivity follows, manifesting as low urinary $\mathrm{pH}^{11}$

Stone patients with normal BMI have been previously reported on, but the goal of the current study was not to report on stone analysis in normal BMI patients or a general population of patients (a population that is a mixture of individuals with normal and abnormal BMI) with stone disease since this is widely covered in the literature. It is well known that $80 \%$ of renal stones are composed of calcium oxalate, $10 \%-15 \%$ uric acid, and the rest are composed of calcium phosphate and cystine stones ( $1 \%-3 \%$ in most populations). The incidence in Saudi Arabia of both diseases is known to be high: approximately $7 \%-10 \%$ with a lifetime risk of $20 \%$ for stone disease, and about $35.5 \%$ of the entire population for obesity. ${ }^{2,12-14}$ Upon urine microscopic examination, the urine crystal predominately seen in the Saudi local population is uric acid crystal. ${ }^{5,12}$

Given the findings in this study, it is recommended that for each individual presenting with urolithiasis, weight and height should be measured and then BMI calculated and used as a simple but relevant indicator of stone composition. Weight reduction should be advised as part of general stone preventive measures. Future research into the underlying pathophysiology of this relationship should be undertaken, which may ultimately enhance preventive and therapeutic measures. With the escalating incidence in obesity among populations worldwide, not only should the field anticipate and plan for increased prevalence of renal stones, but it should also be prepared to manage an increase in the prevalence of stones composed of oxalate and uric acid in patients with increased BMI.

A limitation of this study was the relatively small sample size due to collections from only obese and overweight patients. Further future reports should use a larger sample size. To collect larger numbers of stone samples from this specific population prospectively for analysis might mean using a longer study timeframe. Another limitation was the use of wet chemical semiquantitative analysis for renal stone analysis. The authors agree that the gold standards in stone analysis are infrared spectrometry and X-ray diffraction methods, which require special equipment and training. ${ }^{6}$ However, the refined modern technology using wet chemical semiquantitative analysis still has its role in renal stone analysis. ${ }^{8}$ It is encouraged that other researchers in the field of stone disease repeat this study on the same overweight and obese population, but utilize different stone analysis methodology.

\section{Conclusion}

This report confirms that kidney stones are formed mainly of calcium oxalate and uric acid in overweight and obese patients with nephrolithiasis. The data presented supports the inclusion of caloric intake reduction and weight control in the medical and surgical management plan of urolithiasis in overweight and obese individuals.

\section{Acknowledgments}

Dr Mostafa Tayeb contributed to data collection and Prof HMA Farsi, Prof AMS Tayib, Dr A Sayyad, Dr T Abolmagd, Dr M Rezk, and Dr A Twairgi from the Department of Urology at King Abdulaziz University Hospital contributed patients who were enrolled into this study.

\section{Disclosure}

The authors report no conflicts of interest in this work.

\section{References}

1. Romero V, Akpinar H, Assimos DG. Kidney stones: a global picture of prevalence, incidence, and associated risk factors. Rev Urol. 2010; 12(2-3):e86-e96.

2. Trinchieri A, Curhan G, Karlsen S, Wu KJ. Epidemiology. In: Segura J, Conort P, Khoury S, Pak C, Preminger GM, Tolley D, editors. Stone Disease. 1st International Consultation on Stone Disease; July 4-5, 2001; Paris, France. Paris: Health Publications; 2003:13-29.

3. Knoll T. Epidemiology, pathogenesis, and pathophysiology of urolithiasis. Eur Urol Suppl. 2010;9(12):802-806.

4. Taylor EN, Stampfer MJ, Curhan GC. Obesity, weight gain, and the risk of kidney stones. JAMA. 2005;293(4):455-462.

5. Mosli HA, Mosli HH. Increased body mass index is associated with larger renal calculi. Urology. 2012;80(5):974-979.

6. Gambaro G, Ferraro PM, Capasso G. Calcium nephrolithiasis, metabolic syndrome and the cardiovascular risk. Nephrol Dial Transplant. 2012; 27(8):3008-3010.

7. Strohmaier WL, Wrobel BM, Schubert G. Overweight, insulin resistance and blood pressure (parameters of the metabolic syndrome) in uric acid urolithiasis. Urol Res. 2012;40(2):171-175.

8. Assimos DG, Chew B, Hatch M, et al. Evaluation of the stone former. In: Denstedt J, Khoury S, editors. Stone Disease. 2nd International Consultation on Stone Disease; September 5, 2007; Paris, France. Paris: Health Publications; 2008:31-55.

9. Aydogdu O. Urinary stone disease and obesity: different pathologies sharing common biochemical mechanisms. World J Nephrol. 2012;1(1):12-15. 
10. Mossetti G, Rendina D, Benvenuto D, et al. Metabolic syndrome and nephrolithiasis: can we hypotize a common background? Clin Cases Miner Bone Metab. 2008;5(2):114-117.

11. Maalouf NM, Sakhaee K, Parks JH, Coe FL, Adams-Huet B, Pak CY. Association of urinary $\mathrm{pH}$ with body weight in nephrolithiasis. Kidney Int. 2004;65(4):1422-1425.

12. Mosli HA, Farsi HMA, Al-Zimaity MF, Alvarez MST. Staghorns, large, solitary and multiple renal calculi in native Saudis: a clinical study. Saudi Med J. 1997;18(4):367-373.
13. de la Rosette J, Conort P, Desai M, et al. Treatment of renal stone. In: Denstedt J, Khoury S, editors. Stone Disease. 2nd International Consultation on Stone Disease; September 5, 2007; Paris, France. Paris: Health Publications; 2008:137-238.

14. Al-Nozha MM, Al-Mazrou YY, Al-Maatouq MA, et al. Obesity in Saudi Arabia. Saudi Med J. 2005;26(5):824-829.

\section{Publish your work in this journal}

Research and Reports in Urology is an international, peer-reviewed, open access journal publishing original research, reports, editorials, reviews and commentaries on all aspects of adult and pediatric urology in the clinic and laboratory including the following topics: Pathology, pathophysiology of urological disease; Investigation and treatment of
Dovepress

urological disease; Pharmacology of drugs used for the treatment of urological disease. The manuscript management system is completely online and includes a very quick and fair peer-review system, which is all easy to use. Visit http://www.dovepress.com/testimonials.php to read real quotes from published authors.

Submit your manuscript here: http://www.dovepress.com/research-and-reports-in-urology-journal 